\title{
Real-World Evidence From More Than 1000 Patients Treated With Adalimumab For Moderate-to-Severe Psoriasis in the Czech Republic
}

\author{
Martina Kojanova · Petra Cetkovska · Daniela Strosova • \\ Jorga Fialova · Petr Arenberger · Tomas Dolezal · Spyridon Gkalpakiotis (D) • \\ The BIOREP Study Group
}

Received: December 22, 2020 / Accepted: February 2, 2021 / Published online: March 5, 2021

(C) The Author(s) 2021

\section{ABSTRACT}

Introduction: The study aimed to evaluate the real-world effectiveness of adalimumab as well as investigate the persistence of treatment and identify factors, which may affect it.

Methods: More than 1150 patients (4363.1 patient-years) with psoriasis who had been treated with adalimumab since the start of the BIOREP registry in the Czech Republic were included in this analysis. Treatment effectiveness was defined as improvement in Psoriasis Area and Severity Index (PASI). The analysis was

Members of "The BIOREP Study Group" are listed in the "Acknowledgements" section.

M. Kojanova $(\bowtie) \cdot J$. Fialova

Department of Dermatovenereology, First Faculty of Medicine and General University Hospital, Charles University, Prague, Czech Republic

e-mail: kojanova.martina@vfn.cz

P. Cetkovska

Department of Dermatovenereology, Faculty of Medicine and University Hospital, Charles

University, Pilsen, Czech Republic

P. Arenberger · S. Gkalpakiotis

Department of Dermatovenereology, Third Faculty of Medicine, Charles University and Kralovske Vinohrady University Hospital, Prague, Czech Republic

D. Strosova $\cdot$ T. Dolezal

Value Outcomes, Prague, Czech Republic performed during the years 2005 and 2018 . Patients were on on-label dose.

Results: After 12 and 96 months of therapy, $84 \%$ and $88 \%$ of patients had a $75 \%$ reduction in PASI score from baseline, respectively. Drug survival was analyzed according to the number of previous biological therapies, and results showed $75 \%$ and $58.1 \%$ survival rate for biologically naïve patients in the 20th and 80th month of treatment, respectively. The negative predictors of adalimumab survival were the female gender, obesity, baseline PASI score and the number of previous biological therapies.

Conclusions: Baseline factors including PASI, number of previous biological therapies, and sex were associated with shorter adalimumab survival. This long-term study shows that adalimumab is effective and has high treatment persistence.

Keywords: Adalimumab; BIOREP; Long-term effectiveness; Persistence of treatment; Psoriasis; Registries 


\section{Key Summary Points}

Why carry out this study?

Patients included in randomized controlled clinical trials does not always reflect the type of patients treated in reallife due to strict inclusion and exclusion criteria.

Adalimumab is the biologic with the highest representation in national registries.

The study aims to describe the patient cohort treated with adalimumab (HUMIRA $®$ ) as well as data related to treatment, drug survival, and reasons for discontinuation in more than 1000 patients in real-life.

\section{What was learned from the study?}

The real-world effectiveness of adalimumab was high with $65 \%$ of patients achieving PASI 90 after 12 months therapy and more than $70 \%$ after 6 years.

The significant negative predictors of adalimumab survival were female sex, obesity, high baseline PASI score, and the number of previous biological therapies.

Adalimumab remains a golden standard with high treatment persistence despite the fast-expanding armamentarium of psoriasis therapies with different mechanisms of actions.

\section{DIGITAL FEATURES}

This article is published with digital features, including a summary slide, to facilitate understanding of the article. To view digital features for this article go to https://doi.org/10.6084/ m9.figshare.13626329.

\section{INTRODUCTION}

Psoriasis is an immune-mediated, genetic skin disorder associated with both a physical and psychological burden. The disease manifests mainly in the skin and joints but also affects many other organs and tissues and long-term treatment is required [1-3].

Long-term therapy for psoriasis may be impaired by a gradual loss of effectiveness, which can lead to treatment discontinuation. Identifying factors that affect biological drug survival (i.e., the time from drug initiation until drug discontinuation) can help in treatment optimization. A recent meta-analysis of thirteen cohort studies by Mourad et al. demonstrated that female gender and obesity predicts earlier discontinuation of biological treatment and, surprisingly, concomitant psoriatic arthritis predicts longer biological drug survival [4].

A "patient registry" is a structured set of observational data from patients who share a specific disease or medical condition. The main advantage of patient registries is the ability to offer data on specific diseases, including uncommon conditions and comorbidities, gathered from patients in a "real-world" setting. As of 2018, there were 13 registries for psoriasis patients in Europe [5]. BIOREP, which started in 2005 , is the psoriasis registry in the Czech Republic that evaluates effectiveness and safety of long-term biological treatment. Among other parameters, Dermatology Life Quality Index (DLQI), Psoriasis Area and Severity Index (PASI), and Body Surface Area (BSA) values are followed to assess the long-term usefulness of biologics for psoriasis [6].

Adalimumab (Humira, AbbVie Inc., North Chicago, IL), a fully human anti-tumor necrosis factor (TNF)-alfa monoclonal antibody, was approved for the treatment of moderate-to-severe chronic plaque psoriasis in adults who have either failed to respond, have an intolerance to, or are contradicted for other systemic therapies [7]. It was approved by the National Institute for Health and Clinical Excellence (NICE) in 2008 for use by the UK National Health Service (NHS) [8]. It has also been approved by most of individual Health Technology Assessment (HTA) 
agencies across Europe. Currently, adalimumab is the anti-TNF-alfa with the longest history and highest representation in national registries [9].

Recently, the term drug survival (or treatment persistence) was defined as the time period when patients remain under treatment with a specific therapy, and it can be used as an overall marker of treatment success and treatment adherence. It simultaneously represents information on drug effectiveness, drug safety, and patient satisfaction [3].

The study aims to describe the patient cohort taking adalimumab (HUMIRA $\underline{\circledR}$ ) as well as data related to treatment, drug survival, and reasons for discontinuation in more than 1,000 patients.

\section{METHODS}

\section{Study Setting and Patient Population}

In this retrospective study data from BIOREP registry in the Czech Republic were used. Patients with psoriasis who received at least one dose of adalimumab between 2005 and 2018 were analyzed. The patients met criteria for reimbursement of biological therapy from the public health insurance. Patients were treated with adalimumab according to the standard treatment regimen, $80 \mathrm{mg}$ s.c. at week $0,40 \mathrm{mg}$ at week 1 and then $40 \mathrm{mg}$ every other week.

Data were collected in a standardized format using anonymous electronic case report form (eCRF). The data collected patients' demographic characteristics (age, gender, and body mass index), family history of psoriasis, duration and severity of the disease, presence of psoriatic arthritis, prior systemic and/or biological treatments, standardized measures of health status (PASI, BSA and DLQI) and patients' comorbidities.

PASI score was evaluated at the initiation of adalimumab treatment (month 0 ), in month 3 , in month 6 and then every 6 months. Effectiveness was evaluated as a change in PASI score from baseline (PASI 75, PASI 90 and PASI 100).

Patient-level data used for this analysis were de-identified and Institutional Review Board approval was not required for this study. All patients gave written informed consent. The study adhered to the principles of declaration of Helsinki.

\section{Statistical Analysis}

For purposes of this study, epidemiological data, disease severity, comorbidities, and previous treatments were summarized using descriptive statistics. Category variables are expressed using the number of patients in the groups and the percentage of the total number of patients analyzed. Continuous variables are described using mean and standard deviation. Kaplan-Meier non-parametric survival curves were used for comparative analysis of drug survival. The Cox proportional hazard model was used to analyze the impact of the patient's sex, age, body mass index (BMI), duration of psoriasis, number of comorbidities, PASI, DLQI, biological therapy naïve status, and efalizumab treatment on drug survival. The selection of variables was based on the variables of interest, which should not be omitted from the model, and selected variables which are significant or correlated with drug survival. Both one-dimensional and two-dimensional exploratory analyses were performed. The level of significance was set at $5 \%$. Statistical analysis was performed using STATA 15.1 software (StataCorp, College Station, TX, USA).

\section{RESULTS}

\section{Patient Demographics and Previous Treatment}

As of 15 December 2018, 1,157 patients with at least one dose of adalimumab treatment from the BIOREP registry were analyzed, representing 4,363.1 patient-years (PY) of adalimumab exposure $(63.2 \%$ patients still being treated at the end of the observed period). The analyzed cohort consisted of $714(61.7 \%)$ men and 443 $(38.3 \%)$ women. At the time of diagnosis, the mean patient age was 23.7 years; the mean patient age at the time of adalimumab treatment initiation was 46.7 years. The mean 
Table 1 BIOREP-Demographic data, psoriasis, and characteristics of comorbidities at the time of enrollment

\begin{tabular}{|c|c|c|}
\hline Number of patients & & 1157 \\
\hline Sex & Men & $714(61.7 \%)$ \\
\hline \multirow[t]{2}{*}{ Age } & At the time of diagnosis $(N=1147)$ & $23.7(13.0)$ \\
\hline & At the time of adalimumab & $46.7(12.3)$ \\
\hline \multirow[t]{3}{*}{ Duration [years] } & Of psoriasis $(N=1147) @ @$ & $27.5(12.3)$ \\
\hline & To the first biologics $(N=1147)$ & $21.7(11.7)$ \\
\hline & In the registry & $5.7(3.4)$ \\
\hline Positive family history of psoriasis & & $512(44.3 \%)$ \\
\hline Nail psoriasis $(N=1151)$ & & $278(24.2 \%)$ \\
\hline Psoriatic arthritis & & $473(40.9 \%)$ \\
\hline \multirow[t]{5}{*}{$\mathrm{BMI}^{\mathrm{a}}(N=1140)$} & & $28.7(5.4)$ \\
\hline & Overweight (25-30) & $442(38.8 \%)$ \\
\hline & Obese I (30-35) & $286(25.1 \%)$ \\
\hline & Obese II (35-40) & $94(8.2 \%)$ \\
\hline & Obese III $(>40)$ & $35(3.1 \%)$ \\
\hline \multirow[t]{3}{*}{ PASI $^{\mathrm{b}}$ at the time of adalimumab $(N=1153)$} & & $17.1(8.2)$ \\
\hline & Biologically naïve & $18.8(7.8)$ \\
\hline & Biologically non-naïve & $13.1(7.9)$ \\
\hline \multirow[t]{3}{*}{$\mathrm{BSA}^{\mathrm{c}}$ at the time of adalimumab $(N=838)$} & & $29.3(18.9)$ \\
\hline & Biologically naïve & $30.4(18.5)$ \\
\hline & Biologically non-naïve & $25.1(19.9)$ \\
\hline \multirow[t]{3}{*}{ DLQI $^{\mathrm{d}}$ at the time of adalimumab $(N=472)$} & & $17.6(6.8)$ \\
\hline & Biologically naïve & $18.3(6.6)$ \\
\hline & Biologically non-naïve & $13.2(6.5)$ \\
\hline \multirow[t]{3}{*}{ Number of comorbidities } & 0 & $374(32.4 \%)$ \\
\hline & 1 & $280(24.2 \%)$ \\
\hline & $\geq 2$ & $503(43.5 \%)$ \\
\hline \multirow[t]{7}{*}{ Comorbidities } & Hypertension & $418(36.1 \%)$ \\
\hline & Obesity & $415(35.9 \%)$ \\
\hline & Hyperlipidemia & $343(29.6 \%)$ \\
\hline & Hepatic disease & $204(17.6 \%)$ \\
\hline & Diabetes mellitus & $145(12.5 \%)$ \\
\hline & Depression & $79(6.8 \%)$ \\
\hline & Thyroid dysfunction & $75(6.5 \%)$ \\
\hline
\end{tabular}


Table 1 continued

\begin{tabular}{lll}
\hline Number of patients & & $\mathbf{1 1 5 7}$ \\
\hline & Coronary artery disease & $52(4.5 \%)$ \\
& Neurologic condition & $45(3.9 \%)$ \\
& Malignancy & $15(1.3 \%)$ \\
& Inflammatory bowel disease & $12(1 \%)$ \\
& Latent tuberculosis & $8(0.7 \%)$ \\
Previous biological therapy & Without previous biological therapy & $806(69.7 \%)$ \\
& One other biological therapy & $259(22.4 \%)$ \\
Previous systemic treatment & More than two other biological therapies & $92(8.0 \%)$ \\
& Acitretin & $873(75.5 \%)$ \\
Previous phototherapy treatment & Methotrexate & $852(73.6 \%)$ \\
Finished adalimumab treatment & Cyclosporine & $610(52.7 \%)$ \\
\hline
\end{tabular}

Results are shown as count (\%) or mean (SD)

a BMI Body Mass Index

b PASI Psoriasis Area and Severity Index

c $B S A$ Body Surface Area

d DLQI Dermatology Life Quality Index

duration of the active form of the disease was 27.5 years. The mean duration of the adalimumab treatment is 3.8 years (SD/Standard deviation 3.0 years). Table 1 presents patient demographics data, comorbidities, and previous treatments; $512(44.3 \%)$ patients had a positive family history of psoriasis.

In the analyzed cohort, 473 (40.9\%) patients were diagnosed with psoriatic arthritis, and 160 (33.8\%) were diagnosed with nail psoriasis.

The average BMI was $28.7 \mathrm{~kg} / \mathrm{m}^{2}$, with $75.2 \%$ of the patients being either overweight or obese at baseline.

The mean baseline PASI score at the onset of adalimumab treatment was $17.1 \pm 8.2$, and the mean DLQI was $17.6 \pm 6.8$, indicating high severity of both psoriasis and impairment of the quality of life. Of the evaluated patients, only $32.4 \%$ did not report any comorbidity; $24.2 \%$ presented with one, and $43.5 \%$ presented with two or more comorbidities.
A total of 806 patients (69.7\%) did not have any previous biological therapy, $22.4 \%$ patients received one treatment and $8.0 \%$ received two or more different treatments. The most common previous systemic treatments were acitretin $(75.5 \%)$, methotrexate $(73.6 \%)$, and cyclosporine (52.7\%); additionally, 991 (85.7\%) patients were previously treated with phototherapy.

\section{Response and Failure to Adalimumab Treatment}

A total of 426 patients (36.8\%) discontinued therapy, the mean duration of their treatment was 1.7 years (from the initiation of adalimumab treatment to the discontinuation). The reasons for discontinuation were analyzed, with more than one reason for discontinuation per patient. A total of 52 patients (12.2\%) did not 
Table 2 Reasons for discontinuation of therapy $(N=426)$

\begin{tabular}{|c|c|}
\hline Reasons for drug discontinuation ${ }^{a}$ & Number (\%) \\
\hline Ineffectiveness & $280(65.7 \%)$ \\
\hline From the 16 th week ${ }^{\mathrm{b}}$ & $251(89.6 \%)$ \\
\hline Until the 16 th $^{\text {week }}{ }^{\mathrm{b}}$ & $29(10.4 \%)$ \\
\hline Adverse events ${ }^{c}$ & $75(17.6 \%)$ \\
\hline Non-compliance & $31(7.3 \%)$ \\
\hline Deaths $^{\mathrm{d}}$ & $2(0.5 \%)$ \\
\hline $\begin{array}{l}\text { a } 52 \text { patients (12.2\%) did not have } \\
\text { b } \% \text { calculated from the number } \\
\text { ineffectiveness } \\
\text { c } 6 \text { patients ( } 8.0 \% \text { ) had malignan } \\
\text { phoma, kidney cancer, colorectal ca } \\
\text { and two prostate cancers); } 4 \text { patients } \\
\text { (recurrent infections); } 3 \text { patients ( } 4 . \\
\text { diseases (Parkinson's disease, multip } \\
\text { tigo); } 3 \text { patients ( } 4.0 \% \text { ) had diseases } \\
\text { vessels (coronary heart disease anc } \\
\text { patients ( } 2.7 \% \text { ) had liver disease (he } \\
\text { (1.3\%) had psychiatric illness (mani } \\
\text { (1.3\%) had kidney disorder (renal ins } \\
\text { (2.7\%) had other AE (cholecystol } \\
\text { unclear etiology); } 53 \text { patients (70.7\%) } \\
\text { specified } \\
\text { d Both patients had two reasons }\end{array}$ & $\begin{array}{l}\text { listed } \\
\text { atients citing } \\
\text { odgkin's lym- } \\
\text { hyroid cancer } \\
\text { had infection } \\
\text { d neurological } \\
\text { rosis and ver- } \\
\text { eart and blood } \\
2 \text { strokes); } 2 \\
\text { hy); } 1 \text { patient } \\
\text { der); } 1 \text { patient } \\
\text { cy); } 2 \text { patients } \\
\text { and rash of } \\
\text { t have the AE } \\
\text { ontinuation- } \\
\text { a death caused } \\
\text { arction) }\end{array}$ \\
\hline
\end{tabular}

have the reason listed and two reasons were recorded in 14 patients (3.3\%), which means a total of 440 reasons for discontinuation. Loss of effectiveness was the major reason $(280 ; 65.7 \%)$ followed by adverse events (AE) $(75 ; 17.6 \%)$ and non-compliance $(31 ; 7.3 \%)$. From 280 patients who discontinued adalimumab treatment due to loss of effectiveness a total of 265 patients $(94.6 \%)$ continued on other biological therapies. Among the $\mathrm{AE}$, malignancies, infections, neurological diseases or diseases of the heart and blood vessels were recorded. Table 2 summarizes the reasons for drug treatment discontinuation.

A total of 221 patients (19.1\%) received concomitant methotrexate during adalimumab treatment, of whom 128 patients $(57.9 \%)$ had
PsA. None of patients was on a long-term combination. Methotrexate was used or as a "safety bridge" during the initiation of adalimumab and was stopped after response of adalimumab was seen or was used as a concomitant therapy due to the psoriatic arthritis and was stopped after remission of arthritis was achieved.

The average PASI scores for all patients treated with adalimumab are presented in Fig. 1. The proportion of patients achieving an improvement in PASI of at least $75 \%, 90 \%$, and $100 \%$ from baseline (PASI 75, PASI 90, PASI 100) are shown for a 96-month observation period. After 12 months of therapy, PASI 75, 90 and 100 was observed in $84 \%, 65 \%$ and $38 \%$ of patients, respectively. The proportion of patients with improvement was even higher after 72 months of therapy (PASI 75, 90 and 100 in 91\%, 77\% and $43 \%$ of patients, respectively). At the end of the 96-month observation period there were 75 patients with available data with $88 \%, 76 \%$ and $37 \%$ in PASI 75, 90 and 100, respectively. Due to the small number of patients with observation longer than 96 months, Fig. 1 is shown for this period only.

\section{Adalimumab Survival}

Survival estimates were analyzed according to the number of previous biological therapies. Due to the low number of patients in treatment lines no. 4 and no. 5, these were merged into one group. Patients previously treated with efalizumab $(n=72)$ were not included in the analysis, as the treatment with efalizumab could not have been considered as treatment failure due to the recommendation of the European Medicines Agency (EMA) to discontinue the marketing authorization and all patients were therefore switched to other drugs.

The persistence was calculated using the Kaplan-Meier method and is illustrated as a survival curve, see Fig. 2. The estimates revealed a $75.6 \%$ survival rate for biologically-naïve patients in the 20th month of the treatment (i.e. patients with adalimumab as the first biological therapy), in the 80th month of treatment the survival rate was $58.1 \%$. In patients 


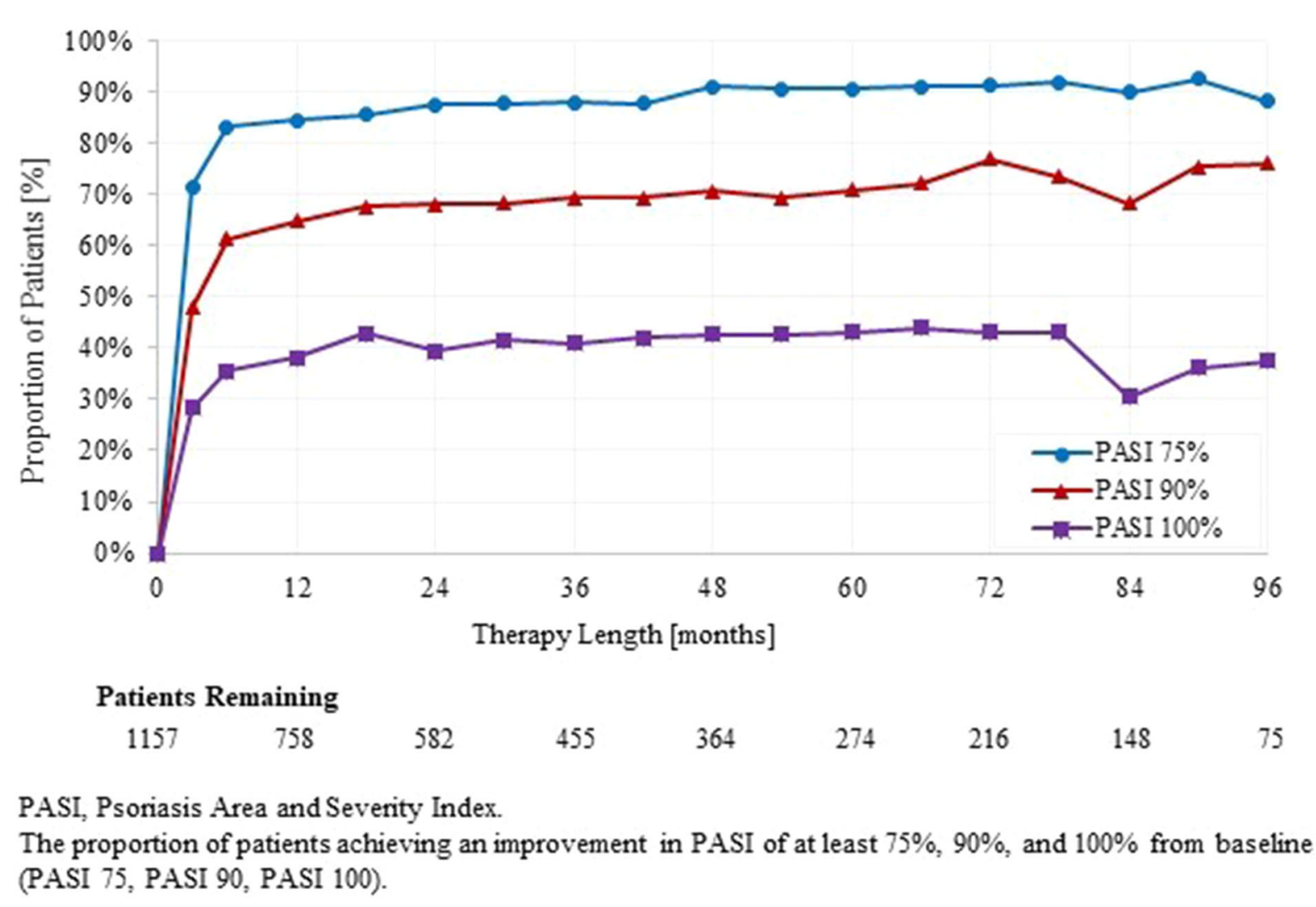

Fig. 1 Treatment response based on PASI

who had adalimumab as the second biological therapy, the survival rate in the 20th month of the treatment was $66.7 \%$, in the 80th month it was $50.1 \%$.

\section{Predictors of Adalimumab Survival}

Variables that were analyzed for their association with adalimumab survival and reference standards for categorical variables are presented in Table 3. Both categorical (sex of the patient, BMI, number of comorbidities, number of previous biological therapies, and efalizumab treatment) and continuous explanatory variables (age, duration of psoriasis, and PASI at the time of adalimumab treatment initiation) were analyzed in this multivariate model. For better interpretation, continuous variables were transposed so that the final hazard ratio (HR) corresponds to the effect of a ten-unit increase (HR $>1.0)$ or decrease $(\mathrm{HR}<1.0)$ in the continuous explanatory variables.
The significant negative predictors of adalimumab survival were female sex, obesity, baseline PASI score at the time of adalimumab treatment initiation, and the number of previous biological therapies. Being female increased the risk of discontinuation by $82 \%$. Also, a higher PASI score at the adalimumab treatment initiation increases the risk by $20 \%$ with every additional 10 points of PASI. In patients who had received 3 or 4 previous biological therapies before initiation of adalimumab treatment, the risk of discontinuation was more than threefold compared to patients who received adalimumab as their first biological therapy.

The only significant positive predictor of adalimumab survival was the duration of psoriasis, which reduced the risk of discontinuation by $9 \%$ for every 10 years. 


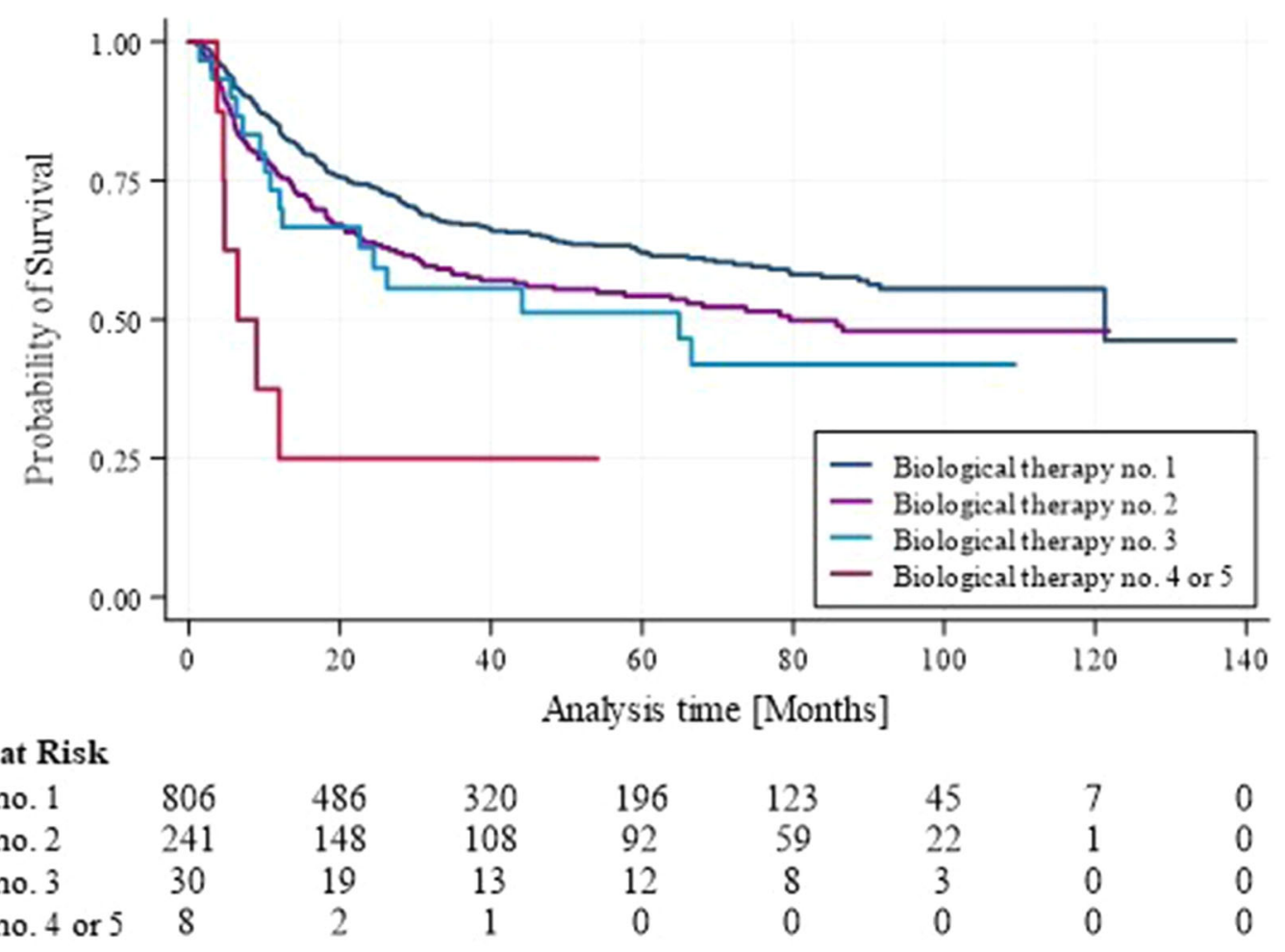

Fig. 2 Survival probability on biological treatment according to treatment lines

\section{Number at Risk \\ Therapy no. 1 \\ Therapy no. 2 \\ Therapy no. 3 \\ Therapy no. 4 or 5 \\ DISCUSSION}

$\begin{array}{cc}806 & 486 \\ 241 & 148 \\ 30 & 19 \\ 8 & 2\end{array}$

Despite the fact that patients in the Czech registry for biological therapy of psoriasis typically started adalimumab more than 20 years after the psoriasis diagnosis and that patients starting adalimumab had both high disease severity and low quality-of-life scores, the real-world effectiveness of adalimumab was high with more than $70 \%$ of patients reaching PASI 90 and $40 \%$ reaching PASI 100.

In our study, the probability of survival on adalimumab decreased with increasing number of different previous therapies. This was further supported by a cost-effectiveness study of biological treatment sequences in the treatment of psoriasis, proposing to start the therapy with adalimumab or ustekinumab [10]. The fact, that the number and type of previous biological therapies for psoriasis and psoriatic arthritis can influence treatment discontinuation was recently described by Yiu et al. [11]; however, in their study, unlike ours, previous treatment with adalimumab was a positive predictor of drug survival.

Our results regarding PASI scores showed rapid improvement immediately after the commencement of adalimumab therapy. Another study focused on the improvement of quality of life while on adalimumab showed similar results. It found not only a rapid decrease in the DLQI but also a significant change, by week 4, in PASI scores ( $p$ value $<0.001$ ) of biologically naïve patients [12].

Recently, several studies were performed with the goal of finding predictors for drug survival related to biological therapy of psoriasis. In general, our findings regarding negative predictors of drug survival correspond well with those from other countries and registries. Obesity, as a negative predictor of drug survival, was also found in a meta-analysis by Mourad et al. [4]. This same work also found that being female was a negative predictor for drug survival on biologics, mainly because of the occurrence of adverse events. The higher drug persistence 
Table 3 Results of multivariate Cox regression $(N=1129)$

\begin{tabular}{|c|c|c|c|c|}
\hline Independent variables & & $N$ (failure) & $\operatorname{HR}^{a}(95 \% \mathrm{CI})^{a}$ & $p$ value \\
\hline \multirow[t]{2}{*}{ Sex } & Male & $698(217)$ & 1 (reference) & - \\
\hline & Female & $431(198)$ & $1.82(1.49-2.22)$ & $<0.001$ \\
\hline Age at the time of adalimumab & & $1129(415)$ & $0.99(0.91-1.09)$ & 0.860 \\
\hline \multirow[t]{5}{*}{ Categorial BMI } & Normal weight $(<25)$ & $279(86)$ & 1 (reference) & - \\
\hline & Overweight $(25-30)$ & $439(147)$ & $1.28(0.97-1.69)$ & 0.087 \\
\hline & Obese I (30-35) & $282(122)$ & $1.65(1.19-2.29)$ & 0.003 \\
\hline & Obese II $(35-40)$ & $94(44)$ & $1.74(1.16-2.61)$ & 0.008 \\
\hline & Obese III $(>40)$ & $35(16)$ & $1.57(0.90-2.77)$ & 0.115 \\
\hline Duration of psoriasis & & $1129(415)$ & $0.91(0.83-0.99)$ & 0.029 \\
\hline \multirow[t]{3}{*}{ Number of comorbidities } & 0 & $356(106)$ & 1 (reference) & - \\
\hline & 1 & $275(107)$ & $1.14(0.85-1.54)$ & 0.384 \\
\hline & $\geq 2$ & $498(202)$ & $1.15(0.85-1.56)$ & 0.366 \\
\hline PASI at the time of adalimumab & & $1129(415)$ & $1.20(1.07-1.35)$ & 0.002 \\
\hline \multirow[t]{4}{*}{ Previous biological therapy } & 0 & $792(255)$ & 1 (reference) & - \\
\hline & 1 & $250(117)$ & $1.59(1.26-2.00)$ & $<0.001$ \\
\hline & 2 & $67(30)$ & $1.75(1.09-2.80)$ & 0.019 \\
\hline & 3 or 4 & $20(13)$ & $3.50(1.82-6.74)$ & $<0.001$ \\
\hline \multirow[t]{2}{*}{ Efalizumab treatment } & No & $1057(383)$ & 1 (reference) & - \\
\hline & Yes & $72(32)$ & $0.78(0.47-1.27)$ & 0.313 \\
\hline
\end{tabular}

a HR Hazard Ratio, CI Confidence Interval

Bold values indicate statistically significant

of males on biological therapy was also found in a retrospective analysis of patients in Hungary [13]. Additionally, the lower response to biological therapy by females was also observed in a longitudinal study of therapy effectiveness in the BADBIR registry [14]. Their findings were also adjusted to the negative impact of low employment status and smoking.

Adverse events, as a reason for adalimumab treatment discontinuation, were seen in $17.6 \%$ of cases in our study; however, in a study by Inzinger et al., a much lower percentage of treatment discontinuation due to AEs was reported. They reported 17 AEs (3.7\%) discontinuations in 460 adalimumab treatment cycles [15]. In the BIOBADADERM registry, 144 AEs and 39 serious AEs were associated with adalimumab discontinuation among 712 adalimumab treatment cycles [16].

Retrospective design and the absence of a control group are the main limitations of our analysis. Another limitation is due to the fact, that some historical data was obtained from the old version of the registry and some information could not be longer obtained.

\section{CONCLUSION}

This study presents the demographics of psoriasis and psoriatic arthritis patients treated with adalimumab, as well as information regarding 
adalimumab treatment, drug survival, and reasons for adalimumab discontinuation in a reallife setting.. The analysis, which was based on data from the BIOREP registry of psoriasis patients in the Czech Republic, shows that adalimumab remains a golden standard with high treatment persistence despite the fast-expanding armamentarium of psoriasis therapies with new mechanisms of actions.

\section{ACKNOWLEDGEMENTS}

BIOREP Study Group Members: Zdenek Antal, Jirina Bartonova, Linda Blahova, Petra Brodska, Dominika Diamantova, Hana Duchkova, Karel Ettler, Olga Filipovska, Petra Gkalpakioti, Martina Grycova, Jaroslav Hoffmann, Jiri Horazdovsky, Eva Horka, Eduard Hrncir, Jaromira Janku, Renata Kopova, Iva Lomicova, Alena Machovcova, Hana Malikova, Miroslav Necas, Helena Nemcova, Jitka Osmerova, Marie Policarova, Veronika Slonkova, Alena Stumpfova, Jaroslav Sevcik, Jan Sternbersky, Jirí Stork, Katerina Svarcova, Katerina Tepla, Martin Tichy, Hana Tomkova, Yvetta Vantuchova, Vladimir Vasku, Ivana Vejrova.

Funding. No funding or sponsorship was received for this study or publication of this article.

Authorship. All named authors meet the International Committee of Medical Journal Editors (ICMJE) criteria for authorship for this article, take responsibility for the integrity of the work as a whole, and have given their approval for this version to be published.

Disclosures. Martina Kojanova, Petra Cetkovska, Spyridon Gkalpakiotis, Petr Arenberger, Jorga Fialova ad Tomas Dolezal have served as consultants, speakers, or investigators for Abbvie, Celgene, Eli Lilly, Janssen, Merc Serono, Leo Pharma, Novartis, Pfizer, and UCB. Daniela Strosova declares that she has no conflict of interest.
Compliance with Ethics Guidelines. Patient-level data used for this analysis were deidentified and Institutional Review Board approval was not required for this study. All patients gave written informed consent. The study adhered to the principles of declaration of Helsinki.

Data Availability. The datasets generated analyzed during the current study are available from the corresponding author on reasonable request.

Open Access. This article is licensed under a Creative Commons Attribution-NonCommercial 4.0 International License, which permits any non-commercial use, sharing, adaptation, distribution and reproduction in any medium or format, as long as you give appropriate credit to the original author(s) and the source, provide a link to the Creative Commons licence, and indicate if changes were made. The images or other third party material in this article are included in the article's Creative Commons licence, unless indicated otherwise in a credit line to the material. If material is not included in the article's Creative Commons licence and your intended use is not permitted by statutory regulation or exceeds the permitted use, you will need to obtain permission directly from the copyright holder. To view a copy of this licence, visit http://creativecommons.org/licenses/by$\mathrm{nc} / 4.0 /$.

\section{REFERENCES}

1. Boehncke W-H, Schön MP. Psoriasis. The Lancet. 2015;386(9997):983-94.

2. Menter A. Psoriasis and psoriatic arthritis treatment. Am J Manag Care. 2016;22(8 Suppl):s225237.

3. Costanzo A, Malara G, Pelucchi C, Fatiga F, Barbera $G$, Franchi A, et al. Effectiveness end points in realworld studies on biological therapies in psoriasis: systematic review with focus on drug survival. Dermatol Basel Switz. 2018;234(1-2):1-12.

4. Mourad A, Straube S, Armijo-Olivo S, Gniadecki R. Factors predicting persistence of biologic drugs in 
psoriasis: a systematic review and meta-analysis. $\mathrm{Br}$ J Dermatol. 2019;181(3):450-8.

5. Amin M, Lee EB, Bhutani $\mathrm{T}$, Wu JJ. Review of European registries for psoriasis. J Dermatol Treat. 2019;30(3):227-36.

6. Kojanova M, Fialova J, Cetkovska P, Gkalpakiotis S, Jircikova J, Dolezal T, et al. Characteristics and risk profile of psoriasis patients included in the Czech national registry BIOREP and a comparison with other registries. Int J Dermatol. 2017;56(4):428-34.

7. Humira $40 \mathrm{mg}$ solution for injection in pre-filled pen-summary of Product Characteristics (SmPC) (emc) [Internet]. [cited 2020 Mar 30]. Available from: https://www.medicines.org.uk/emc/product/ 7986

8. Overview $\mid$ Adalimumab for the treatment of adults with psoriasis | Guidance | NICE [Internet]. NICE; [cited 2020 Mar 30]. Available from: https://www. nice.org.uk/guidance/ta146? unlid= 8346068882016119175149

9. Strober B, Crowley J, Langley RG, Gordon K, Menter A, Leonardi C, et al. Systematic review of the realworld evidence of adalimumab safety in psoriasis registries. J Eur Acad Dermatol Venereol. 2018;32(12):2126-33.

10. Klijn SL, van den Reek JMPA, van de Wetering G, van der Kolk A, de Jong EMGJ, Kievit W. Biologic treatment sequences for plaque psoriasis: a costutility analysis based on 10 years of Dutch realworld evidence from BioCAPTURE. Br J Dermatol. 2018;178(5):1181-9.

11. Yiu ZZN, Mason KJ, Hampton PJ, Reynolds NJ, Smith $\mathrm{CH}$, Lunt $\mathrm{M}$, et al. Drug survival of adalimumab, ustekinumab, and secukinumab in patients with psoriasis: a prospective cohort study from the british association of dermatologists biologics and immunomodulators register (BADBIR). Br J Dermatol. 2020.

12. Leman J, Walton S, Layton AM, Ward KA, McBride $S$, Cliff S, et al. The real world impact of adalimumab on quality of life and the physical and psychological effects of moderate-to-severe psoriasis: a UK prospective, multicenter, observational study. J Dermatol Treat. 2020;31(3):213-21.

13. Pogácsás L, Borsi A, Takács P, Remenyik É, Kemény L, Kárpáti S, et al. Long-term drug survival and predictor analysis of the whole psoriatic patient population on biological therapy in Hungary. J Dermatol Treat. 2017;28(7):635-41.

14. Warren RB, Marsden A, Tomenson B, Mason KJ, Soliman MM, Burden AD, et al. Identifying demographic, social and clinical predictors of biologic therapy effectiveness in psoriasis: a multicentre longitudinal cohort study. $\mathrm{Br} \mathrm{J}$ Dermatol. 2019;180(5):1069-76.

15. Inzinger M, Wippel-Slupetzky K, Weger W, Richter L, Mlynek A, Fleischander B, et al. Survival and effectiveness of tumour necrosis factor-alpha inhibitors in the treatment of plaque psoriasis under daily life conditions: report from the psoriasis registry Austria. Acta Derm Venereol. 2016;96(2): 207-12.

16. Belinchón I, Ramos JM, Carretero G, Ferrándiz C, Rivera R, Daudén E, et al. Adverse events associated with discontinuation of the biologics/classic systemic treatments for moderate-to-severe plaque psoriasis: data from the Spanish Biologics Registry, Biobadaderm. J Eur Acad Dermatol Venereol JEADV. 2017;31(10):1700-8. 